\title{
Associated factors of blood transfusion for Caesarean sections in pure placenta praevia pregnancies
}

\author{
Vitaya Titapant $^{1}$, MD, Thananan Chongsomboonsuk ${ }^{1}$, MD
}

INTRODUCTION This study aimed to evaluate associated factors of blood transfusion for Caesarean sections in pure placenta praevia pregnancies.

METHODS A case-control study was conducted among 405 pregnant women with placenta praevia who underwent Caesarean delivery between August 2004 and December 2013. 135 of the women received blood transfusions. Another 270 women who did not receive any blood transfusion were randomly selected and served as controls. Maternal demographic data, reproductive history, antepartum profiles and obstetric outcomes were compared between the two groups. RESULTS Women in the case group were significantly more likely to be multiparous, deliver at a gestational age of less than 37 weeks, have a prior Caesarean delivery, experience preoperative bleeding and anaemia, and have major and anterior placenta praevia $(p<0.05)$. Multivariate analysis demonstrated that significant, independently associated factors of blood transfusion were: previous Caesarean section (adjusted odds ratio [OR] 2.30, 95\% confidence interval [CI] 1.36-3.90), anterior placenta praevia (adjusted OR 2.30, 95\% Cl 1.15-4.60), major placenta praevia (adjusted OR 2.39, 95\% Cl 1.34-4.22), preoperative bleeding of more than $250 \mathrm{~mL}$ (adjusted OR 6.11, 95\% Cl 2.35-15.90), preoperative anaemia (adjusted OR 2.31, 95\% Cl 1.34-4.00) and emergency Caesarean section (adjusted OR 2.14, 95\% Cl 1.08-4.22). CONCLUSION Previous Caesarean section, anterior placentation, major placenta praevia, preoperative bleeding of more than $250 \mathrm{~mL}$, preoperative anaemia and emergency Caesarean section were independent factors that increased the risk of blood transfusion for Caesarean section in pure placenta praevia pregnancies.

Keywords: associated factors, blood transfusion, Caesarean section, placenta praevia, risk factors

\section{INTRODUCTION}

Placenta praevia, one of the most serious obstetric complications, increases the risk of maternal and perinatal morbidity due to massive bleeding during the antepartum and peripartum period..$^{(1-3)}$ The global prevalence of placenta praevia has been reported to be 5.2 per 1,000 pregnancies, with the highest rate reported in Asia at 12.2 per 1,000 pregnancies. ${ }^{(4)}$

International guidelines and literature reviews suggest that the optimal management of placenta praevia pregnancies is Caesarean section at the proper gestational age in a unit with adequate facilities and available blood supplies. ${ }^{(5-9)}$ However, there is no definite data on the type or volume of blood that should be used for preoperative preparation. In many hospitals, including our institute, four units of packed red blood cells are cross matched, then two units are delivered to be on standby in the operating room. The efficacy of this practice is unclear.

Among two decades of reports about placenta praevia, only two studies reported directly on the associated factors of blood transfusion during Caesarean delivery in placenta praevia pregnancies. One study found that the risk factors were advanced maternal age, repeated dilatation and curettage, and complete placenta praevia, ${ }^{(10)}$ while the other study found dissimilar results, delivery at 32-35 weeks of gestation and Caesarean hysterectomy. ${ }^{(11)}$ Most of the previous reports did not exclude cases of placenta accreta from the placenta praevia subjects, analysing them simultaneously. Placenta accreta has been strongly associated with severe maternal morbidity, especially massive intraoperative haemorrhage and the need for blood transfusion, so that it seems to be the important confounding factor.

With advances in medical technologies, the technique of greyscale ultrasonography is now able to provide high accuracy for prenatal diagnosis of invasive placentation with a sensitivity of 90.72\% (95\% confidence interval [Cl] 87.2-93.6) and specificity of $96.94 \%$ (95\% Cl 96.3-97.5). ${ }^{(12)}$ Additionally, using colour Doppler and magnetic resonance imaging can improve diagnostic sensitivity. In cases of suspicious placenta accreta, a prompt, multidisciplinary team approach should be used, with considerable requirements for preoperative blood component preparation for intraoperative complications. In contrast, in cases of placenta praevia, there is less requirement for blood components.

Due to the conflicting results of these previous studies and their inclusion of placenta accreta cases, the risk factors for blood transfusion during Caesarean section in pure placenta praevia pregnancies are still unclear. Hence, this study aimed to determine the risk factors of blood transfusion for Caesarean section in pure placenta praevia pregnancies, which would aid in preoperative planning.

\section{METHODS}

This case-control study was conducted after approval by our institutional review board. We included subjects with placenta praevia who underwent Caesarean delivery at a gestational age of

${ }^{1}$ Department of Obstetrics and Gynaecology, Faculty of Medicine Siriraj Hospital, Mahidol University, Bangkok, Thailand

Correspondence: A/Prof Vitaya Titapant, Consultant, Department of Obstetrics and Gynaecology, Faculty of Medicine Siriraj Hospital, Mahidol University, 2 Prannok Road, Bangkoknoi, Bangkok, Thailand 10700. vitaya.tit@mahidol.ac.th 
more than 28 weeks between August 2004 and December 2013 at Siriraj Hospital, Bangkok, Thailand. Patients were excluded if any of the following conditions were met: (a) multiple pregnancies; (b) intrauterine fetal death; (c) severe preeclampsia; (d) placenta accreta; or (e) other antepartum conditions that altered maternal haemodynamic status, including maternal shock, severe anaemia or haematocrit less than $21 \%$, platelet count less than 100,000, abnormal coagulogram, use of anticoagulative drugs, or severe medical illness such as heart disease, chronic renal disease and autoimmune disease.

The case group comprised patients who received a transfusion with at least one unit of blood during a Caesarean operation until the postoperative hospitalisation period. The control group was randomly selected from the remaining patients, who did not receive a blood transfusion, to establish a case-control ratio of $1: 2$. Throughout the study period, a total of 716 patients met the inclusion criteria. In total, 135 (18.9\%) patients who received a blood transfusion were included in the case group, and 270 patients were randomly selected from the remaining patients by a computer program to form the control group, making up a total of 405 patients.

For Caesarean sections, a blood transfusion was always indicated when the patient's haemoglobin level was less than $6 \mathrm{~g} / \mathrm{dL}$ and was rarely indicated when it was greater than $10 \mathrm{~g} / \mathrm{dL}$. In patients whose haemoglobin level was $7-10 \mathrm{~g} / \mathrm{dL}$, the decision to perform blood transfusion was made according to the clinical judgment of the attending obstetrician or anaesthesiologist, after considering the patient's haemodynamic status, volume of haemorrhage, anaemic symptoms and medical conditions.

Maternal demographic data, reproductive history, antepartum profiles and obstetric outcomes were carefully extracted from the medical records and compared between the case and control patients. Classifications of placenta praevia, placental location and fetal presentation were made by ultrasonogram, performed primarily within one week of the operation by a trained specialist in the hospital's Maternal-Foetal Medicine Unit.

Complete or partial placenta praevia was considered 'major placenta praevia', while placenta praevia marginalis or low-lying placenta were considered 'minor placenta praevia'. Anaemia at the time of first antenatal care and preoperative anaemia were defined as haematocrit less than $33 \%$. Preoperative blood loss was defined as the total amount of bleeding during the episode for which the patient was transferred to the operating room, and was estimated by trained physicians and documented in the medical records.

Statistical analysis was performed using SPSS version 16.0 (SPSS, Chicago, IL, USA). Continuous data was presented as means and compared using Student's $t$-test. All variables were subdivided into two or three categories prior to conducting univariate analysis. A logistic regression model was used for the multivariate analysis. The outcomes were quantified as percentages and odds ratios (ORs) with a 95\% confidence interval. A value of $p<0.05$ was considered statistically significant.

\section{RESULTS}

The basic characteristics and obstetric outcomes of all 405 subjects (135 case and 270 control) are shown in Table I.
Table I. Basic characteristics of the subjects.

\begin{tabular}{|c|c|c|c|}
\hline \multirow[t]{2}{*}{ Characteristic } & \multicolumn{2}{|c|}{ Mean \pm SD } & \multirow[t]{2}{*}{ p-value } \\
\hline & $\begin{array}{l}\text { No transfusion } \\
(n=270)\end{array}$ & $\begin{array}{l}\text { Transfusion } \\
(n=135)\end{array}$ & \\
\hline \multicolumn{4}{|c|}{ Demographic/antepartum profile } \\
\hline Age (yr) & $33.0 \pm 5.0$ & $32.2 \pm 5.3$ & 0.478 \\
\hline $\begin{array}{l}\text { Gestational } \\
\text { age (wk) }\end{array}$ & $36.8 \pm 2.1$ & $35.6 \pm 3.0$ & $<0.001$ \\
\hline Gravida & $1.9 \pm 1.0$ & $2.3 \pm 1.2$ & 0.002 \\
\hline Parity & $0.5 \pm 0.7$ & $0.8 \pm 0.8$ & 0.598 \\
\hline $\begin{array}{l}\text { Previous } \\
\text { miscarriage }\end{array}$ & $0.3 \pm 0.6$ & $0.4 \pm 0.7$ & 0.006 \\
\hline $\begin{array}{l}\text { Pregestational } \\
\text { BMI }\left(\mathrm{kg} / \mathrm{m}^{2}\right)\end{array}$ & $21.8 \pm 3.3$ & $21.8 \pm 3.7$ & 0.494 \\
\hline $\begin{array}{l}\text { Preoperative } \\
\text { BMI }\left(\mathrm{kg} / \mathrm{m}^{2}\right)\end{array}$ & $26.9 \pm 3.6$ & $27.3 \pm 3.7$ & 0.865 \\
\hline First ANC Hct (\%) & $35.5 \pm 3.1$ & $34.6 \pm 3.3$ & 0.894 \\
\hline $\begin{array}{l}\text { Preoperative } \\
\text { Hct (\%) }\end{array}$ & $35.6 \pm 3.1$ & $34.0 \pm 3.3$ & 0.026 \\
\hline $\begin{array}{l}\text { Preoperative } \\
\text { bleeding (mL) }\end{array}$ & $40 \pm 92$ & $212 \pm 332$ & $<0.001$ \\
\hline \multicolumn{4}{|l|}{ Obstetric outcome } \\
\hline $\begin{array}{l}\text { Operative blood } \\
\text { loss }(\mathrm{mL})\end{array}$ & $529 \pm 270$ & $1,387 \pm 944$ & $<0.001$ \\
\hline $\begin{array}{l}\text { Total blood } \\
\text { transfusion (unit) }\end{array}$ & - & $2.0 \pm 1.5$ & $<0.001$ \\
\hline Birth weight (g) & $2,858 \pm 590$ & $2,624 \pm 692$ & 0.004 \\
\hline $\begin{array}{l}\text { Apgar } \\
\text { score (1 min) }\end{array}$ & $8.2 \pm 1.6$ & $6.7 \pm 2.8$ & $<0.001$ \\
\hline $\begin{array}{l}\text { Apgar } \\
\text { score (5 min) }\end{array}$ & $9.6 \pm 1.1$ & $8.9 \pm 1.7$ & $<0.001$ \\
\hline
\end{tabular}

ANC: antenatal care; BMI: body mass index; Hct: haematocrit; SD: standard deviation

Patients in the case group were significantly more likely to be multiparous, deliver at gestational age of less than 37 weeks, have prior miscarriages, and have preoperative bleeding and anaemia ( $p<0.05)$. In the case group, 98 (72.6\%) patients received intraoperative blood transfusions; the remaining subjects received blood transfusions in the postpartum ward. Combined Caesarean hysterectomies were performed in 13 (9.6\%) patients due to uncontrolled bleeding. $4(3.0 \%)$ patients underwent reexploratory laparotomy for hysterectomy due to postoperative haemorrhage from uterine atony.

The results of univariate and multivariate analyses of the risk factors for blood transfusion are shown in Table II. Many factors, including gestational age of less than 37 weeks, multigravida, multiparity, previous Caesarean section, anterior placenta praevia, major placenta praevia, preoperative bleeding of more than $250 \mathrm{~mL}$, preoperative anaemia, history of antepartum blood transfusion and emergency Caesarean section, correlated significantly with blood transfusion in univariate analysis $(p<0.05)$. All significant variables were included in the multivariate analysis to control for potential confounding factors. Multivariate analysis showed that previous Caesarean section, 
Table II. Univariate and multivariate analysis of factors associated with blood transfusion.

\begin{tabular}{|c|c|c|c|c|c|c|}
\hline \multirow[t]{2}{*}{ Parameter } & \multicolumn{2}{|c|}{ No. (\%) } & \multicolumn{2}{|c|}{ Univariate analysis } & \multicolumn{2}{|c|}{ Multivariate analysis } \\
\hline & $\begin{array}{l}\text { No transfusion } \\
(\mathbf{n}=\mathbf{2 7 0})\end{array}$ & $\begin{array}{l}\text { Transfusion } \\
(n=135)\end{array}$ & OR $(95 \% \mathrm{Cl})$ & p-value & $\begin{array}{l}\text { Adjusted } \\
\text { OR }(95 \% \mathrm{CI})\end{array}$ & p-value \\
\hline \multicolumn{7}{|l|}{ Demographic data } \\
\hline \multicolumn{7}{|l|}{ Age (yr) } \\
\hline$<35$ & $170(63.0)$ & $82(60.7)$ & ref & & & \\
\hline$\geq 35$ & $100(37.0)$ & $53(39.3)$ & $1.17(0.77-1.78)$ & 0.470 & & \\
\hline \multicolumn{7}{|l|}{ Gestational age (wk) } \\
\hline $28-34$ & $39(14.4)$ & $40(29.6)$ & $2.82(1.67-4.77)$ & $<0.001$ & $1.10(0.50-2.48)$ & 0.812 \\
\hline $35-36$ & $45(16.7)$ & $30(22.2)$ & $1.88(1.09-3.23)$ & 0.022 & $1.08(0.52-2.25)$ & 0.834 \\
\hline$\geq 37$ & $186(68.9)$ & $65(48.1)$ & ref & & ref & \\
\hline \multicolumn{7}{|l|}{ Gravida } \\
\hline 1 & $115(42.6)$ & $40(29.6)$ & ref & & ref & \\
\hline $2-4$ & $149(55.2)$ & $87(64.4)$ & $1.68(1.07-2.62)$ & 0.023 & $0.87(0.40-1.91)$ & 0.727 \\
\hline$\geq 5$ & $6(2.2)$ & $8(5.9)$ & $3.83(1.25-11.73)$ & 0.018 & $1.59(0.32-7.97)$ & 0.575 \\
\hline \multicolumn{7}{|l|}{ Parity } \\
\hline 0 & $161(59.6)$ & $53(39.3)$ & ref & & ref & \\
\hline 1 & $85(31.5)$ & $62(45.9)$ & $2.26(1.44-3.55)$ & $<0.001$ & $1.36(0.60-3.07)$ & 0.460 \\
\hline$\geq 2$ & $24(8.9)$ & $20(14.8)$ & $2.71(1.40-5.26)$ & 0.003 & $1.37(0.50-3.82)$ & 0.540 \\
\hline \multicolumn{7}{|l|}{ Reproductive history } \\
\hline \multicolumn{7}{|l|}{ Previous miscarriage } \\
\hline No & $201(74.4)$ & $93(68.9)$ & ref & & & \\
\hline Yes & $69(25.6)$ & $42(31.1)$ & $1.23(0.78-1.94)$ & 0.384 & & \\
\hline \multicolumn{7}{|l|}{ Previous C-section } \\
\hline No & $236(87.4)$ & $100(74.1)$ & ref & & ref & \\
\hline Yes & $34(12.6)$ & $35(25.9)$ & $2.62(1.56-4.45)$ & $<0.001$ & $2.30(1.36-3.90)$ & 0.018 \\
\hline \multicolumn{7}{|l|}{ Previous uterine curettage } \\
\hline No & $223(82.6)$ & $104(77.0)$ & ref & & & \\
\hline Yes & $47(17.4)$ & $31(23.0)$ & $1.41(0.85-2.36)$ & 0.183 & & \\
\hline \multicolumn{7}{|l|}{ History of placenta praevia } \\
\hline No & $267(98.9)$ & $132(97.8)$ & ref & & & \\
\hline Yes & $3(1.1)$ & $3(2.2)$ & $2.02(0.40-10.16)$ & 0.392 & & \\
\hline \multicolumn{7}{|l|}{ Antepartum profile } \\
\hline Pregestational BMI (kg/m²) & $(n=263)$ & $(n=130)$ & & & & \\
\hline$<30$ & $255(97.0)$ & $125(96.2)$ & ref & & & \\
\hline$\geq 30$ & $8(3.0)$ & $5(3.8)$ & $1.28(0.41-3.98)$ & 0.676 & & \\
\hline \multicolumn{7}{|l|}{ Anaemia at 1 st ANC } \\
\hline No & $223(82.6)$ & $111(82.2)$ & ref & & & \\
\hline Yes & $47(17.4)$ & $24(17.8)$ & $1.08(0.63-1.84)$ & 0.783 & & \\
\hline Placental location & $(n=269)$ & & & & & \\
\hline Anterior & $66(24.5)$ & $57(42.2)$ & $2.58(1.65-4.03)$ & $<0.001$ & $2.30(1.15-4.60)$ & 0.002 \\
\hline Posterior & $190(70.6)$ & $70(51.9)$ & ref & & ref & \\
\hline Both sides & $13(4.8)$ & $8(5.9)$ & $1.75(0.69-4.40)$ & 0.237 & $2.00(0.72-5.57)$ & 0.183 \\
\hline \multicolumn{7}{|l|}{ Placenta praevia type } \\
\hline Minor & $98(36.3)$ & $25(18.5)$ & ref & & ref & \\
\hline Major & $172(63.7)$ & $110(81.5)$ & $2.39(1.46-9.92)$ & 0.001 & $2.39(1.34-4.22)$ & 0.003 \\
\hline \multicolumn{7}{|l|}{ Fetal presentation } \\
\hline Vertex & $226(83.7)$ & $105(77.8)$ & ref & & & \\
\hline Others & $44(16.3)$ & $30(22.2)$ & $1.53(0.92-2.56)$ & 0.105 & & \\
\hline
\end{tabular}


Table II. (Contd...)

\begin{tabular}{|c|c|c|c|c|c|c|}
\hline \multirow[t]{2}{*}{ Parameter } & \multicolumn{2}{|c|}{ No. $(\%)$} & \multicolumn{2}{|c|}{ Univariate analysis } & \multicolumn{2}{|c|}{ Multivariate analysis } \\
\hline & $\begin{array}{l}\text { No transfusion } \\
(n=270)\end{array}$ & $\begin{array}{l}\text { Transfusion } \\
(n=135)\end{array}$ & OR $(95 \% \mathrm{CI})$ & p-value & $\begin{array}{l}\text { Adjusted } \\
\text { OR }(95 \% \mathrm{CI})\end{array}$ & p-value \\
\hline \multicolumn{7}{|l|}{ Preoperative condition } \\
\hline Preoperative BMI $\left(\mathrm{kg} / \mathrm{m}^{2}\right)$ & & $(n=134)$ & & & & \\
\hline$<30$ & $220(81.5)$ & $104(77.6)$ & ref & & & \\
\hline$\geq 30$ & $50(18.5)$ & $30(22.4)$ & $1.26(0.76-2.11)$ & 0.359 & & \\
\hline \multicolumn{7}{|l|}{ Preoperative bleeding $(\mathrm{mL})$} \\
\hline 0 & $164(60.7)$ & $49(36.3)$ & ref & & ref & \\
\hline $1-250$ & $96(35.6)$ & $47(34.8)$ & $1.51(0.93-2.42)$ & 0.089 & $0.98(0.52-1.86)$ & 0.950 \\
\hline$\geq 251$ & $10(3.7)$ & $39(28.9)$ & $12.54(5.85-26.89)$ & $<0.001$ & $6.11(2.35-15.90)$ & $<0.001$ \\
\hline \multicolumn{7}{|l|}{ Preoperative anaemia } \\
\hline No & $221(81.9)$ & $87(64.4)$ & ref & & ref & \\
\hline Yes & $49(18.1)$ & $48(35.6)$ & $2.49(1.55-3.98)$ & $<0.001$ & $2.31(1.34-4.00)$ & 0.003 \\
\hline \multicolumn{7}{|c|}{ History of antepartum blood transfusion } \\
\hline No & $268(99.3)$ & $129(95.6)$ & ref & & ref & \\
\hline Yes & $2(0.7)$ & $6(4.4)$ & $6.23(1.24-31.31)$ & 0.026 & $1.53(0.23-10.38)$ & 0.659 \\
\hline \multicolumn{7}{|l|}{ Indication for C-section } \\
\hline Elective & $125(46.3)$ & $33(24.4)$ & ref & & ref & \\
\hline Emergency & $145(53.7)$ & $102(75.6)$ & $2.46(1.57-3.88)$ & $<0.001$ & $2.14(1.08-4.22)$ & 0.029 \\
\hline
\end{tabular}

Value of $\mathrm{n}$ is stated when missing data was excluded from the analysis. ANC: antenatal care; BMI: body mass index; C-section: Caesarean section; Cl: confidence interval; OR: odds ratio; ref: reference group

anterior placenta praevia, major placenta praevia, preoperative bleeding of more than $250 \mathrm{~mL}$, preoperative anaemia and emergency Caesarean section significantly increased the risk of blood transfusion.

Notably, a total of 1,256 units of red cells were matched for preoperative preparations, but only 273 units were transfused to the patients. Only 150 units were required during the intraoperative period, while the remaining 123 units were transfused in the postpartum ward. Of the 405 subjects, 104 patients had excessive blood loss of more than 1,000 mL; $89(85.6 \%)$ of them received a blood transfusion and were classified into the blood transfusion group, whereas $15(14.3 \%)$ patients did not require a blood transfusion. The most common causes of haemorrhage, according to the operative records, were bleeding of the placental sites (39.4\%), uterine atony $(23.1 \%)$ and intraoperative adhesion (10.6\%). 35 (33.7\%) patients experienced haemorrhage from unspecified causes.

\section{DISCUSSION}

Placenta praevia increased the risk of peripartum blood transfusion compared with other obstetric indications for Caesarean section (OR 4.39-26.58). ${ }^{(13,14)}$ The association of peripartum blood transfusion with placenta praevia was first proposed by Oya et $\mathrm{al}^{(10)}$ in a 2008 study in which $43(33 \%)$ of 129 patients with placenta praevia who underwent Caesarean delivery required a blood transfusion. The risk factors for blood transfusion were maternal age greater than 34 years, a history of more than one dilatation and curettage, and complete placenta praevia (ORs 3.7, 4.8 and 26, respectively). ${ }^{(10)}$ Subsequently, Boyle et al ${ }^{(11)}$ reported that 71 (34\%) of 206 patients with placenta praevia received a blood transfusion during Caesarean section but reported the risk factors to be gestational age of 32-35 weeks at delivery and Caesarean hysterectomy (ORs 2.6 and 29.4, respectively). ${ }^{(11)}$ In these studies, $5.5 \%-10.6 \%$ of the placenta praevia patients also presented with placenta accreta, which may be a confounding factor for massive haemorrhage and the need for a blood transfusion. As a result, our transfusion rate in pure placenta praevia pregnancies $(19 \%)$ was lower than those of the aforementioned studies. It is likely that the risk factors for blood transfusion were different in these three studies.

The current case-control study was able to determine important statistical outcomes for multiple risk factors of blood transfusion for Caesarean section in pure placenta praevia pregnancies. This study is the first to present data purely from cases of placenta praevia, excluding all cases of placenta accreta, unlike previous studies. The case-to-control ratio was established at 1:2 to enable appropriate data collection and optimise the power of the study. The criteria for selecting subjects were considered carefully to control for heterogeneity and selection bias; therefore, conditions that could alter the maternal haemodynamic system were also excluded. The baseline characteristics of the subjects in the case and control groups were similar.

According to our multivariate analysis, patients with a previous Caesarean section, anterior placenta praevia or major placenta praevia had twice the risk for blood transfusions, which is similar to the findings in many previous studies. Ayaz and Farooq $^{(15)}$ and Grobman et $\mathrm{al}^{(16)}$ found that maternal morbidity and blood transfusion rates associated with cases of placenta praevia increased in frequency with an increase in the number of previous Caesarean deliveries. Additionally, previous Caesarean 
section is a predisposing factor of massive haemorrhage $(>2,500 \mathrm{~mL})$ in patients with placenta praevia. ${ }^{(17)}$

Cases of major placenta praevia (complete or partial placenta praevia) have been shown to have a significantly higher incidence of maternal complications, including blood transfusion and hysterectomy, than cases of minor placenta praevia (placenta praevia marginalis and low-lying placenta). ${ }^{(18)}$ Both Oya et al ${ }^{(10)}$ and Tuzovic ${ }^{(19)}$ reported that only complete placenta praevia significantly increased the requirement for blood transfusion and hysterectomy.

As the placenta is highly vascularised, a placenta located beneath the incision site during a transplacental Caesarean approach is a possible cause of massive bleeding. Therefore, many studies found that anterior placenta praevia was an independent risk factor for maternal morbidity, including massive haemorrhage, higher rates of blood transfusion and hysterectomy, ${ }^{(20,21)}$ especially in patients who underwent multiple Caesarean deliveries. ${ }^{(22)}$

To our knowledge, there were no previous studies on the relationship between antepartum bleeding and the need for blood transfusions in placenta praevia. Our study found that cases of placenta praevia with preoperative bleeding of more than $250 \mathrm{~mL}$ had a significantly higher risk of blood transfusion than those without. Because an acute antepartum haemorrhage was also the major cause of emergency Caesarean sections, it is reasonable that when ongoing blood loss was considered, unstable emergency patients undergoing emergency Caesarean section had a higher blood requirement compared to stable elective Caesarean patients. Although anaemia was also a risk factor for intraoperative blood transfusion, ${ }^{(23,24)}$ this study implied that preoperative haematocrit was more important than maternal baseline haematocrit in predicting the need for blood transfusion.

The strengths of our study were its large sample and the adjustments made to the study design to control for bias and confounding factors. We were also the first to only examine data from pure placenta praevia pregnancies, which is highly representative of real clinical practice. However, the retrospective nature of the study presented limitations. Firstly, many interesting variables, such as the total amount of antepartum blood loss, a history of tocolytic use and pre-pregnancy haematocrit levels could not be collected due to inadequate information. Secondly, the data in the patients' medical records was documented by many different physicians. Interpretations of the sonographic findings, estimates of blood loss and decisions to initiate blood transfusion were made by multidisciplinary teams of obstetricians and anaesthesiologists, and hence the data may be operator dependent.

Our findings may enable better risk identification, preoperative preparation and patient counselling in women diagnosed with placenta praevia pregnancies who are undergoing Caesarean delivery. In our view, for the patients who do not present with these high-risk factors, fewer units of blood should be cross matched, or type and screen protocol should be used, to reduce the cost, blood stock needed and staff workload.
In conclusion, previous Caesarean section, anterior placenta praevia, major placenta praevia, preoperative bleeding of more than $250 \mathrm{~mL}$, preoperative anaemia and emergency Caesarean section were the factors significantly associated with blood transfusion for Caesarean section in pure placenta praevia pregnancies.

\section{REFERENCES}

1. Crane JMG, Van den Hof MC, Dodds L, Armson BA, Liston R. Maternal complications with placenta previa. Am J Perinatol 2000; 17:101-5.

2. Rosenberg T, Pariente G, Sergienko R, Wiznitzer A, Sheiner E. Critical analysis of risk factors and outcome of placenta previa. Arch Gynecol Obstet 2011; 284:47-51.

3. Sheiner E, Shoham-Vardi I, Hallak M, et al. Placenta previa: obstetric risk factors and pregnancy outcome. J Matern Fetal Med 2001; 10:414-9.

4. Cresswell JA, Ronsmans C, Calvert C, Filippi V. Prevalence of placenta praevia by world region: a systematic review and meta-analysis. Trop Med Int Health 2013; 18:712-24.

5. Minakami H, Maeda T, Fujii T, et al. Guidelines for obstetrical practice in Japan: Japan Society of Obstetrics and Gynecology (JSOG) and Japan Association of Obstetricians and Gynecologists (JAOG) 2014 edition. J Obstet Gynaecol Res 2014; 40:1469-99.

6. Olive EC, Roberts CL, Algert CS, Morris JM. Placenta praevia: maternal morbidity and place of birth. Aust N Z J Obstet Gynaecol 2005; 45:499-504.

7. Oppenheimer L; Maternal Fetal Medicine Committee. Diagnosis and management of placenta previa. J Obstet Gynaecol Can 2007; 29:261-6.

8. Royal College of Obstetricians and Gynaecologists. Placenta Praevia and Placenta Accreta: Diagnosis and Management. RCOG Greentop Guideline No. 27a. September 2018. Available at: https://obgyn.onlinelibrary.wiley.com/doi/ pdf/10.1111/1471-0528.15306. Accessed March 3, 2019.

9. Neilson JP. Interventions for suspected placenta praevia. Cochrane Database Syst Rev 2003; (2):CD001998.

10. Oya A, Nakai A, Miyake H, Kawabata I, Takeshita T. Risk factors for peripartum blood transfusion in women with placenta previa: a retrospective analysis. J Nippon Med Sch 2008; 75:146-51

11. Boyle RK, Waters BA, O'Rourke PK. Blood transfusion for caesarean delivery complicated by placenta praevia. Aust N Z J Obstet Gynaecol 2009; 49:627-30.

12. Society of Gynecologic Oncology; American College of Obstetricians and Gynecologists and the Society for Maternal-Fetal Medicine, Cahill AG, Beigi R, Heine RP, Silver RM, Wax JR. Placenta accreta spectrum. Am J Obstet Gynecol 2018; 219:B2-B16.

13. Chua SC, Joung SJ, Aziz R. Incidence and risk factors predicting blood transfusion in caesarean section. Aust N Z J Obstet Gynaecol 2009; 49:490-3.

14. Onwere C, Gurol-Urganci I, Cromwell DA, et al. Maternal morbidity associated with placenta praevia among women who had elective caesarean section. Eur J Obstet Gynecol Reprod Biol 2011; 159:62-6.

15. Ayaz A, Farooq MU. Risk of adverse maternal and peri-natal outcome in subjects with placenta previa with previous cesarean section. Kurume Med J 2012; 59:1-4.

16. Grobman WA, Gersnoviez R, Landon MB, et al; National Institute of Child Health and Human Development (NICHD) Maternal-Fetal Medicine Units (MFMU) Network. Pregnancy outcomes for women with placenta previa in relation to the number of prior cesarean deliveries. Obstet Gynecol 2007; 110:1249-55.

17. Hasegawa J, Matsuoka R, Ichizuka K, et al. Predisposing factors for massive hemorrhage during Cesarean section in patients with placenta previa. Ultrasound Obstet Gynecol 2009; 34:80-4.

18. Bahar A, Abusham A, Eskandar M, Sobande A, Alsunaidi M. Risk factors and pregnancy outcome in different types of placenta previa. J Obstet Gynaecol Can 2009; 31:126-31

19. Tuzovic L. Complete versus incomplete placenta previa and obstetric outcome. Int J Gynaecol Obstet 2006; 93:110-7.

20. Jang DG, We JS, Shin JU, et al. Maternal outcomes according to placental position in placental previa. Int J Med Sci 2011; 8:439-44.

21. Baba Y, Matsubara S, Ohkuchi A, et al. Anterior placentation as a risk factor for massive hemorrhage during cesarean section in patients with placenta previa. J Obstet Gynaecol Res 2014; 40:1243-8.

22. Young BC, Nadel A, Kaimal A. Does previa location matter? Surgical morbidity associated with location of a placenta previa. J Perinatol 2014; 34:264-7.

23. Rouse DJ, MacPherson C, Landon M, et al; National Institute of Child Health and Human Development Maternal-Fetal Medicine Units Network. Blood transfusion and cesarean delivery. Obstet Gynecol 2006; 108:891-7.

24. Goundan A, Kalra JK, Raveendran A, Bagga R, Aggarwal N. Descriptive study of blood transfusion practices in women undergoing cesarean delivery. J Obstet Gynaecol Res 2011; 37:1277-82. 